\title{
Fibrosing alveolitis and treatment with sulphasalazine
}

\author{
DEWI DAVIES AND ANDREW MacFARLANE
}

From Ransom Hospital, Mansfield, and King's Mill Hospital, Sutton-in-Ashfield

SUMMARY A woman with ulcerative colitis was treated with sulphasalazine and prednisolone. After four months' treatment she began to get short of breath and she died a month later with severe subacute fibrosing alveolitis. It is believed that the lung disease was caused by sulphasalazine and that prednisolone was not able to prevent its development. A reversible form of lung disease has previously been attributed to this drug.

An increasing number of drugs are known to produce lung disease. Jones and Malone (1972) reported a reversible form in a patient treated with sulphasalazine (Salazopyrine). We record a patient who developed and died from fibrosing alveolitis whilst being treated with this drug and prednisolone for ulcerative colitis.

\section{Case History}

S.A., a housewife, aged 47, was well until early in December 1962 when she developed severe diarrhoea with blood and mucus in the stools. When admitted to hospital she felt ill and had 10 motions daily. Low-grade fever and some abdominal tenderness were present but there was no other clinical abnormality. Sigmoidoscopy showed mucopus and blood in the lumen and a granular, velvety mucosa. A barium enema later showed changes typical of ulcerative colitis throughout the colon.

The haemoglobin was $9.5 \mathrm{~g}$ per $100 \mathrm{ml}$ with evidence of iron deficiency; white blood count 10400 per $\mathrm{cmm}$ with $78 \%$ neutrophils, $13 \%$ lymphocytes, $3 \%$ monocytes, and $6 \%$ eosinophils; erythrocyte sedimentation rate $9 \mathrm{~mm}$ in one hour (Westergren); serum albumin $3.9 \mathrm{~g}$ and globulin $3.0 \mathrm{~g}$ per $100 \mathrm{ml}$; electrolytes and urea normal; blood group $0 \mathrm{Rh}$ positive. The chest radiograph showed some calcification in the right hilum.

On 21 December 1962 treatment was started with sulphasalazine $8 \mathrm{~g}$ and prednisolone $15 \mathrm{mg}$ daily and retention enemas of hydrocortisone. By 8 January she was passing only three or four stools daily but sigmoidoscopy still showed severe inflammation and the dose of prednisolone was increased to $30 \mathrm{mg}$ daily. When she was discharged on 1 February she

Received for publication 12 December 1973. still had occasional low-grade fever but felt much better. Sigmoidoscopy showed mild mucosal granularity. She continued with sulphasalazine $6 \mathrm{~g}$ and prednisolone $30 \mathrm{mg}$ daily. When reviewed on 9 March she had two stools daily and had gained some weight. Sigmoidoscopy showed further improvement. She was advised to continue with the same treatment and had no further bowel symptoms.

Shortness of breath began rather suddenly on 10 April 1963. At first it was present on exertion but later it became troublesome at rest. At no time did she have cough, sputum, or wheezing. When she was admitted to hospital on 3 May 1963 she was thin, afebrile, and very dyspnoeic, with breathing of a restrictive pattern. Slight cyanosis was present but no finger clubbing. Extensive coarse crepitations were present over the lower halves of the lungs and

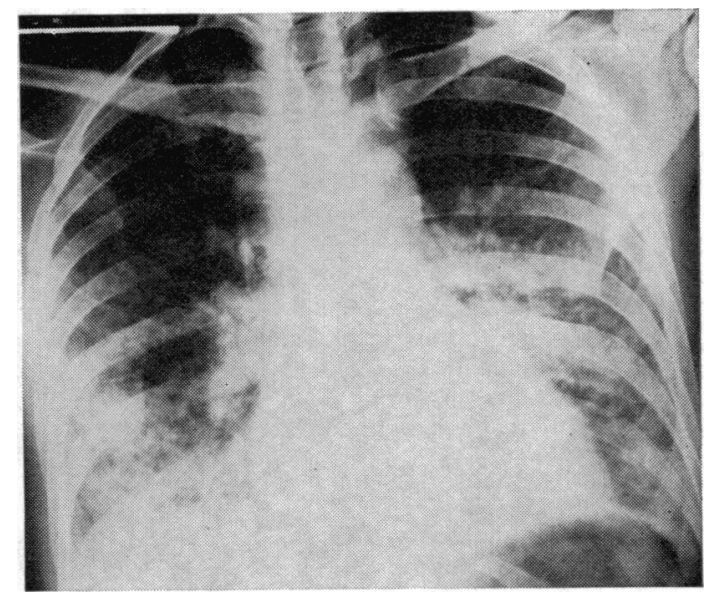

Fig 1 Chest radiograph showing diffuse shadowing in the lower two-thirds of the lungs. 


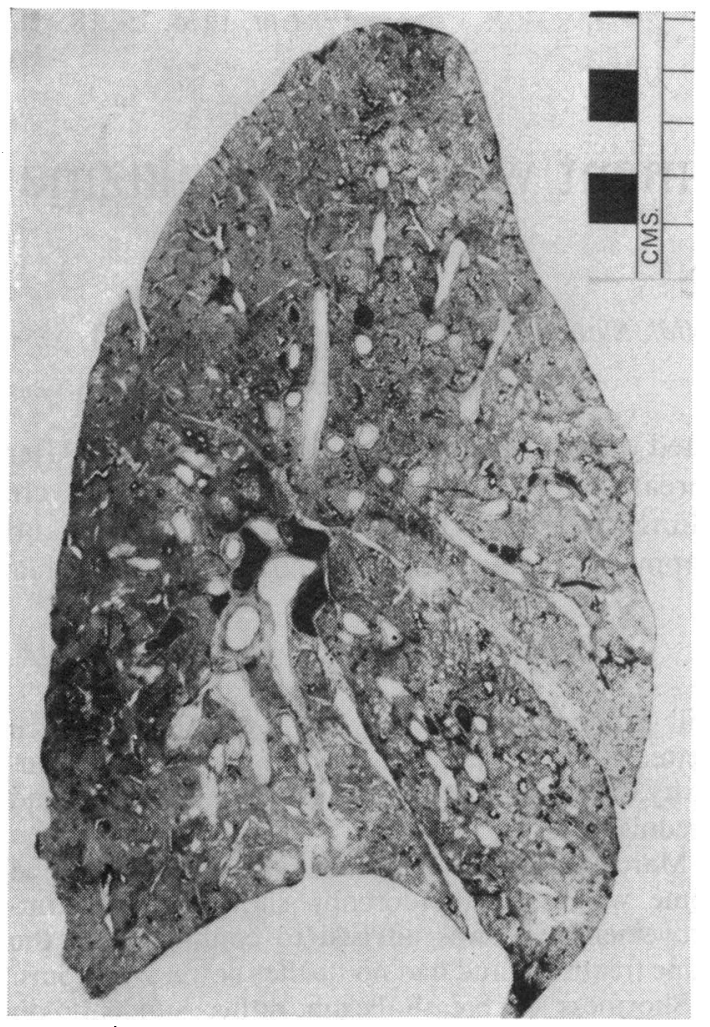

Fig 2

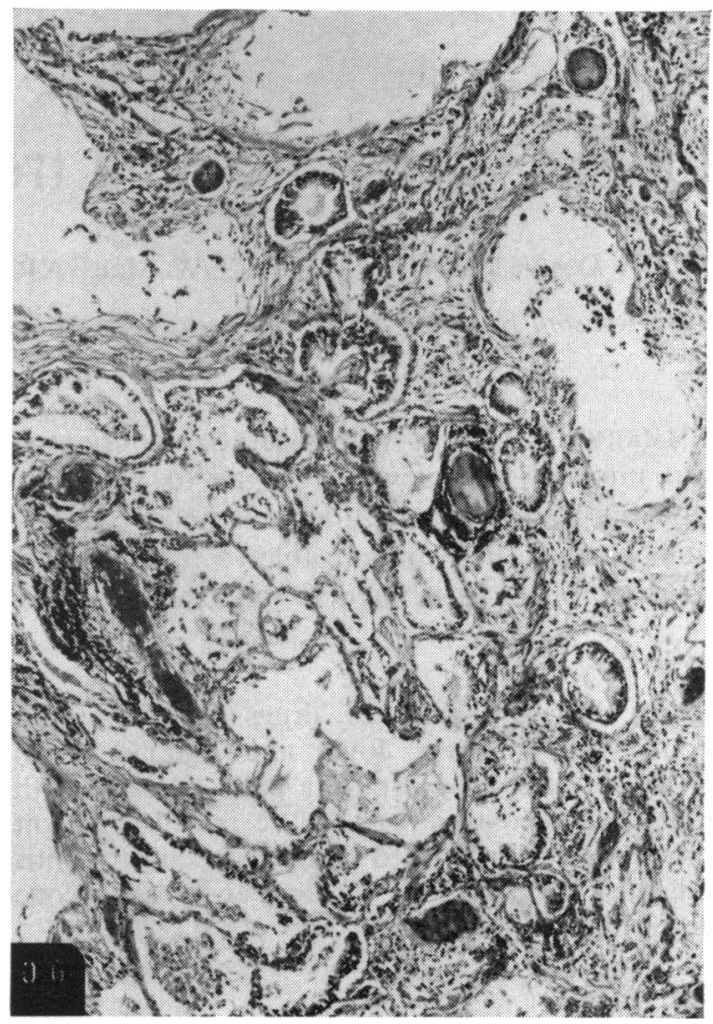

Fig 4

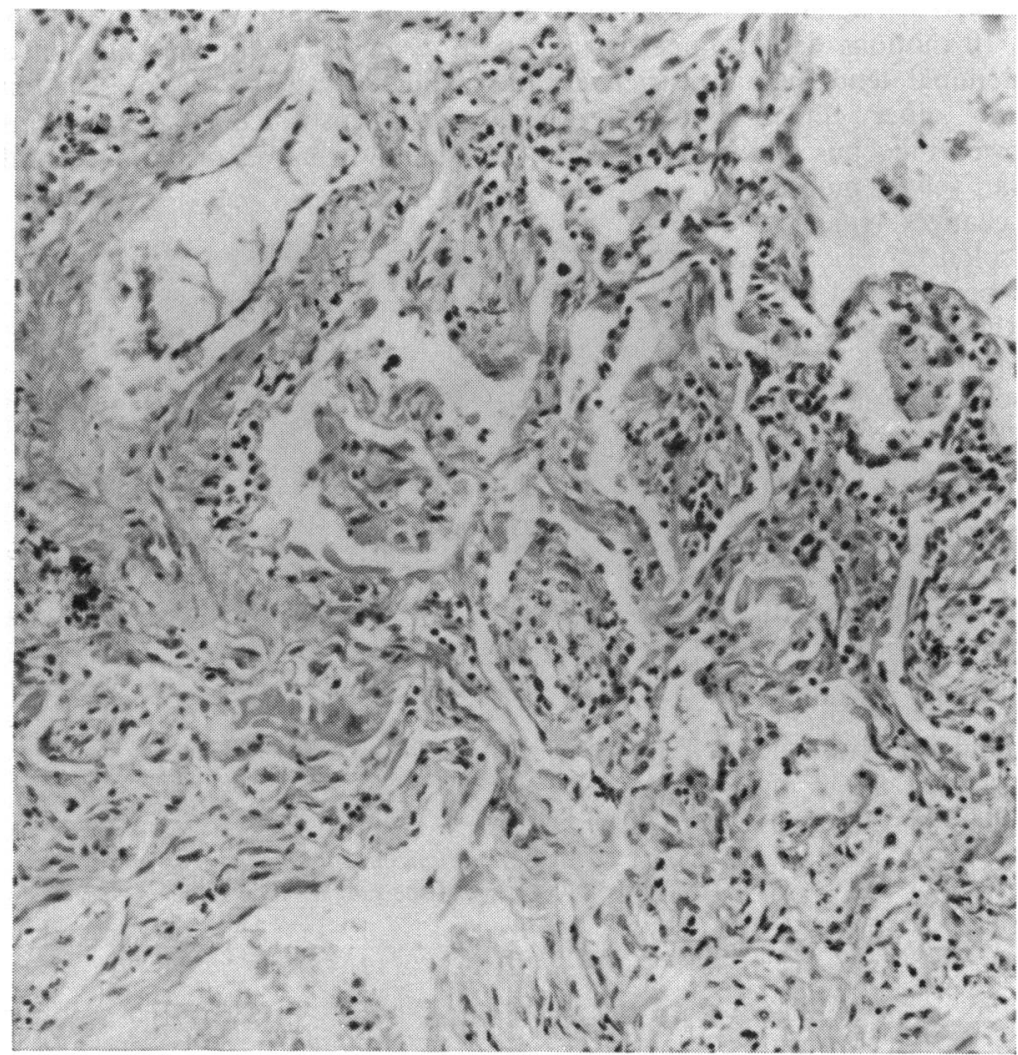

Fig 2 Sagittal section of inflated right lung. It is small and shows diffuse consolidation, mainly in the posterior part of the lower lobe.

Fig 3 The alveoli are filled with mononuclear cells, oedema fluid, and some fibrin and their walls are thickened (× 130).

Fig 4 Alveoli are lined by tall columnar epithelium. Some have normal walls and contain desquamated cells and oedema fluid. Elsewhere there is destruction of the alveolar pattern by fibrosis. The dark solid areas are blood in alveoli and vessels ( $\times 48)$. 
the heart rate was 140 per minute. There was mild swelling of the left calf, with increased warmth and prominent superficial veins. The chest radiograph (fig 1) showed fairly extensive hazy shadowing in the lower two-thirds of the lungs. The electrocardiogram showed sinus tachycardia and tall peaked $P$ waves.

Other findings were: haemoglobin $13.5 \mathrm{~g}$ per $100 \mathrm{ml}$; white blood count 14400 per $\mathrm{cmm}$ with $85 \%$ neutrophils, $8 \%$ lymphocytes, $4 \%$ monocytes, and $3 \%$ eosinophils; erythrocyte sedimentation rate $45 \mathrm{~mm}$ in one hour; serum bilirubin normal; blood culture sterile. The urine contained $90 \mathrm{mg}$ of protein per $100 \mathrm{ml}$ with 5 leucocytes per high-power field and a few granular and hyalogranular casts.

She was treated with oxygen, intravenous heparin followed by oral phenindione, and prednisolone $40 \mathrm{mg}$ daily. After five days antituberculosis drugs were added but she failed to improve and died on 10 May, a month after the onset of dyspnoea.

\section{POSTMORTEM FINDINGS}

The body was that of a thin, middle-aged woman showing slight pitting oedema of the left ankle. The serous sacs were healthy. The heart was dilated and there was slight coronary and aortic atheroma. The left femoral vein contained antemortem thrombus and there was an embolus in each pulmonary artery. There was no ulceration in the large bowel but the mucosa looked thin. The left lung was sectioned at necropsy. It was increased in weight and showed diffuse reddish-brown consolidation of the lower lobe and to a lesser extent of the upper lobe with oedema fluid /exuding on pressure. The right lung was distended via the bronchi with $10 \%$ buffered formalin and sectioned a week later. It was small and showed similar diffuse consolidation maximal in the lower lobe (fig 2).

Histologically there were areas where the alveoli contained mononuclear cells and their walls were thickened due to proliferation of fibroblasts and an increase in reticulin fibres (fig 3). Elsewhere some air spaces contained oedema fluid, red blood cells, and desquamated cells whilst others were lined by epithelium of bronchiolar type (fig 4). There was widespread destruction of the alveolar pattern and there was honeycombing subpleurally (fig 5).

There was no ulceration in the large bowel but the mucosa was thin and there was some loss of glands, in keeping with an inactive phase of ulcerative colitis.

\section{Discussion}

There was no personal or family history of allergy. During her illness she was only known to have taken

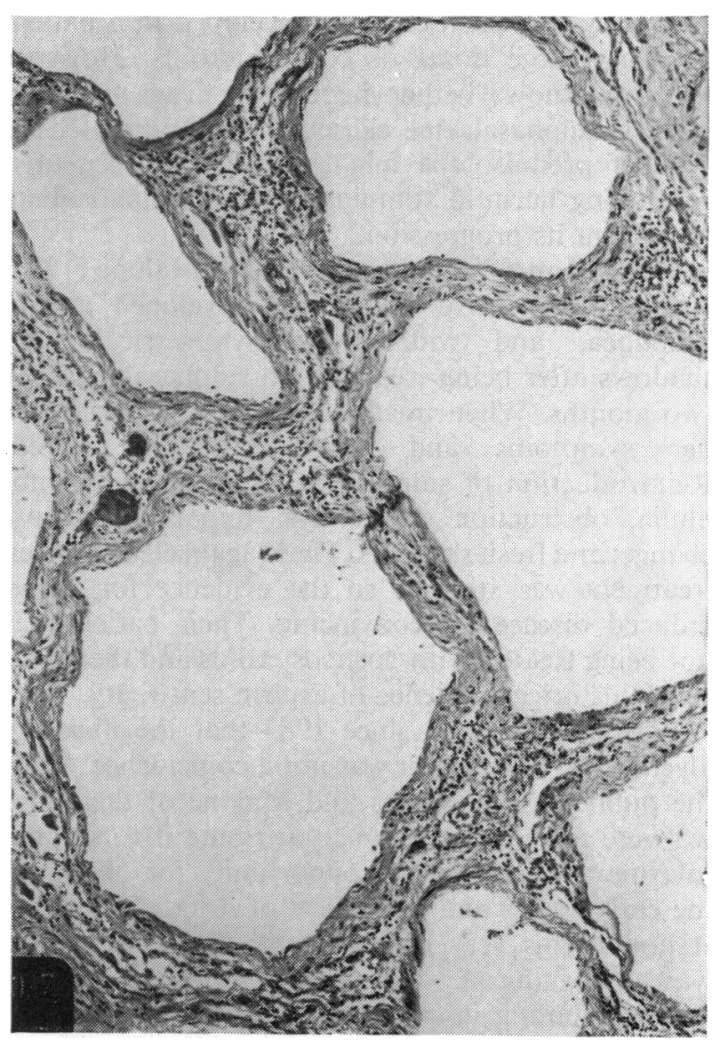

Fig 5 Subpleural honeycombing with complete compression of the intervening alveoli $(\times 48)$

sulphasalazine, prednisolone, ferrous sulphate, and hydrocortisone enemas. When the colitis began she had no respiratory signs and the chest radiograph, even on rescrutiny, showed no abnormality apart from hilar calcification. During her first period in hospital the colitis responded satisfactorily to treatment and she had no symptoms of drug intolerance. She continued to have occasional low-grade fever, as she had done before treatment was started, but this reached $100^{\circ} \mathrm{F}\left(37.8^{\circ} \mathrm{C}\right)$ on only four occasions.

Once shortness of breath began it increased rapidly. Though she had phlebothrombosis in the leg and terminal pulmonary emboli, the major disease was fibrosing alveolitis. The histological features were very similar to the fairly acute cases originally described by Hamman and Rich (1944). Exudative features were prominent and the interstitial thickening appeared to be due to a combination of fibroblastic proliferation and the incorporation of intraalveolar exudates into the walls together with compression of consolidated alveoli by surrounding enlarged air spaces. It is 
surprising that such changes developed in a patient on fairly large doses of corticosteroids. However we do not know whether she took her drugs regularly. Also, if sulphasalazine caused the lung disease, the dose of prednisolone might, in the presence of a continuing harmful stimulus, have been inadequate to prevent its progression.

The patient reported by Jones and Malone (1972) also had ulcerative colitis and developed cough, dyspnoea, and widespread asymmetrical lung shadows after being treated with sulphasalazine for two months. When treatment was stopped she lost her symptoms and the radiograph cleared. Reintroduction of sulphasalazine produced eosinophilia, obstruction of airways, impaired gas exchange, and fresh shadows. These again cleared when treatment was stopped so the evidence for druginduced disease was convincing. Their patient was not being treated with corticosteroids and there was some historical evidence of aspirin sensitivity.

We had suspected since 1963 that the fibrosing alveolitis in our patient was not a coincidence. Until the publication by Jones and Malone of their case we were not in a position to attribute it to sulphasalazine as there was no opportunity for observing the early stages and the effects of drug withdrawal. It now seems very probable that the lung disease was drug-induced. This seems more satisfactory than attributing its presence to chance in a patient with ulcerative colitis. There is no published evidence of an association between the two diseases though there is evidence for an association between fibrosing alveolitis and coeliac disease (Smith, Benson, and Strickland, 1971).

Though a cause can still not be found for the large majority of cases of fibrosing alveolitis, we believe that sulphasalazine can now be added to the previously recognized causative drugs, namely, hexamethonium (Petersen, Dodge, and Helwig, 1959), busulphan (Heard and Cooke, 1968), nitrofurantoin (Rosenow, DeRemee and Dines, 1968), and paraquat (Matthew, Logan, Woodruff, and Heard, 1968).

We are grateful to Dr R. N. Tattersall for information about the earlier stages of the patient's illness.

\section{References}

Hamman, L, and Rich, A. R. (1944). Acute diffuse interstitial fibrosis of the lungs. Bull. Johns Hopk. Hosp., 74, 177-212.

Heard, B. E., and Cooke, R. A. (1968). Busulphan lung. Thorax, 23, 187-193.

Jones, G. R., and Malone, D. N. S. (1972). Sulphasalazine induced lung disease. Thorax, 27, 713-717.

Matthew, H., Logan, A., Woodruff, M. F. A., and Heard, B. (1968). Paraquat poisoning-lung transplantation. Brit. med. J., 3, $759-763$.

Petersen, A. G., Dodge, M., and Helwig, F. C. (1959). Pulmonary changes associated with hexamethonium therapy. Arch. intern. Med., 103, 185-288.

Rosenow, E. C., DeRemee, R. A., and Dines, D. E. (1968). Chronic nitrofurantoin pulmonary reaction. New Engl. J. Med., 279, 1258-62.

Smith, M. J. L., Benson, M. K., and Strickland, I. D. (1971). Coeliac disease and diffuse interstitial lung disease. Lancet, 1, 473-476. 